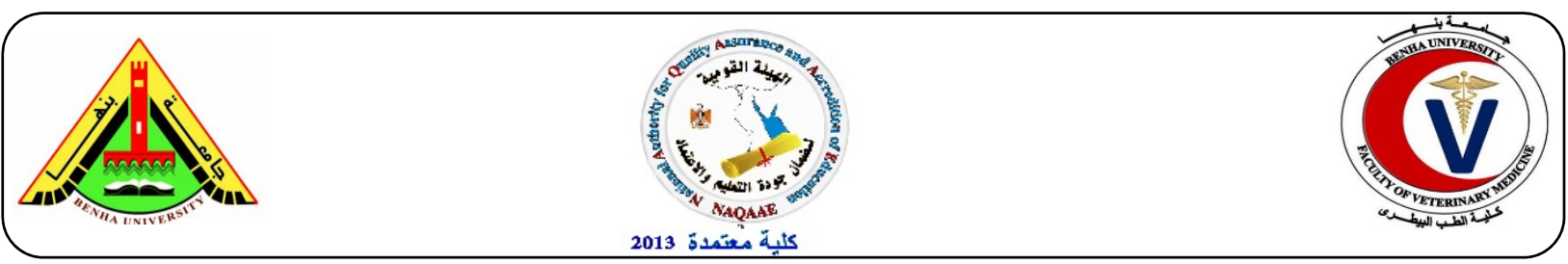

\title{
Decontamination of inoculated chicken carcasses by using some microbial decontaminators \\ Saad, M.S. ${ }^{1}$, Hemmat, M. Ibrahim ${ }^{1}$, Reham, A.Amin ${ }^{1}$, Elshater, M.A. ${ }^{2}$ and Salwa, M. \\ Hafez $^{2}$ \\ ${ }^{1}$ Department of Food Control, Faculty of Veterinary Medicine, Benha University. \\ ${ }^{2}$ Department of Food Hygiene, Animal Health Research Institute, Dokki
}

\section{A B S T R A C T}

This study was conducted to evaluate the efficacy of three decontaminators in reducing the level of contamination in chicken carcasses which had been artificially contaminated. A grand total of forty random samples of raw chicken carcasses were purchased directly from local markets. Chicken samples were then dipped in cultures of the tested microorganisms (Salmonella spp., Staphylococcus aureus, E.coli $\mathrm{O} 157: \mathrm{H} 7$ and L. monoctogens) (10 samples for each microorganism). Then dipped into containers containing distilled water (control), chlorine $30 \mathrm{ppm}, 50 \mathrm{ppm}$ and $70 \mathrm{ppm}$, trisodium phosphate $3 \%, 5 \%$ an $8 \%$ and lactic acid $0.75 \%, 1.25 \%$ and $2 \%$, where the reduction percentage of Salmonella were $26.02 \%, 26.57 \%, 29.16 \%, 34.88 \%, 36.78 \%, 38.01 \%, 35.42 \%, 40.87 \%$ and 54.50 $\%$, respectively, compared to control. while the reduction of Listeria monocytogenes was $16.64 \%$, $20.60 \%, 30.43 \%, 21.74 \%, 21.74 \%, 25.14 \%, 22.87 \%, 30.24 \%$ and $39.89 \%$ respectively . Moreover , the reduction percentages of S. aureus was $14.29 \%, 15.70 \%, 19.58 \%, 8.11 \%, 10.58 \%, 27.69 \%$, $17.28 \%, 21.34 \%$ and $27.87 \%$, respectively . Finally, the reduction percentage of E.coli O157:H7 was $9.56 \%, 16.61 \%, 20.47 \%, 17.45 \%, 21.48 \%, 27.85 \%, 18.12 \%, 19.97 \%$ and $29.70 \%$, respectively.

Keywords: chlorine, TSP, lactic acid, chicken carcasses, decontamination.

(http://www.bvmj.bu.edu.eg)

(BVMJ-28(2): 83-90, 2015)

\section{INTRODUCTION}

$\mathrm{A}$ voiding contamination is one of the greatest challenges in meat hygiene practice to prolong the shelf-life of meat and prevent food poisoning of consumer. A substantial microbial reduction of potentially contaminated fresh poultry can be achieved by decontamination with chlorines, acid and alkaline solutions. Besides general hygienic measures during the slaughter process sodium hypochlorite, lactic acid and trisodium phosphate (TSP) seemed to be the most promising substances to reduce the overall bacterial load. Chlorine is the most frequently used antimicrobial intervention in commercial poultry processing due to its availability, low cost, and efficacy (Northcutt and Jones 2004). In general, chlorine compounds are effective against Gram-positive, Gram-negative, and acidfast bacteria, fungi, and viruses. However, chlorine reacts with organic materials relatively easily and can quickly lose effectiveness (Barbut, 2002, Bremner and Johnstone 1996). Trisodium Phosphate (TSP) is generally recognized as safe by the US (FDA) and has been approved by USDA-FSIS at levels of $8-12 \%$ as an antimicrobial agent on raw chilled poultry carcasses that have been passed for wholesomeness (USDA, 2002). Treatment of poultry carcasses with TSP is effective in reducing populations of food spoilage bacteria as well as foodborne pathogens including Salmonella, Escherichia coli 
O157:H7, Listeria, and Staphylococcus aureus (Capita et al., 2002).

Lactic acid has a thoroughly studied mechanism of action and generally regarded as safe status; several studies demonstrated the effectiveness of lactic acid as an antimicrobial intervention in red meat processing (Hardin et. al., 1995), and lactic acid is commonly used in commercial beef slaughter operations. Other studies have evaluated lactic acid as a poultry processing intervention (Anang et. al., 2007, Bautista et al., 1997, Kanellos and Burriel, 2005 and Okolocha and Ellerbroek, 2005). However, most antimicrobials have not been studied under mobile poultry slaughter conditions. The mechanism of action of organic acids on the microbial cell is not completely understood, but it is hypothesised that it is the undissociated molecule of the acid that is responsible for the antimicrobial activity (Podolak et al., 1996). Therefore this study was planned out to investigate the antimicrobial effect of chlorine ( $30,50,70$ ppm) , TSP( $3 \%, 5 \%, 8 \% 0$ and lactic acid $(0.75 \%, 1.25 \%, 2 \%)$ on chicken carcasses artificially inoculated with S.typhimurium, L.monocytogenes, E.coli $\mathrm{O}_{157: \mathrm{H}_{7}}$ and St.aureus .

\section{MATERIAL AND METHODS}

\subsection{Chicken carcasses:}

A grand total of forty random samples of raw chicken carcasses were purchased directly from local markets. The samples were taken and transferred directly to the laboratory using an ice box under complete aseptic conditions without any delay. The samples were divided into four equal groups (10 samples each). All samples were washed in sterile distilled water.

\subsection{Preparation of microbial suspension:}

Reference strains of S. typhimurium., St. aureus, E.coli O157:H7 and L. monoctogens were obtained from Animal Health Research Institute. Four to five isolated colonies of the tested strains were picked up by sterile inoculating loop and inoculated in sterile peptone water $0.1 \%$ (Merck, Germany) and were then incubated at $37^{\circ} \mathrm{C}$ for $24 \mathrm{hrs}$.

\subsection{Preparation of decontaminators:}

\subsubsection{Chlorine:}

Sodium hypochlorite solution 4\% (Oxford laboratory) was used to prepare $30 \mathrm{pmm}, 50$ $\mathrm{pmm}$ and $70 \mathrm{ppm}$ by dissolving $0.75 \mathrm{ml}$, $1.25 \mathrm{ml}$ and $1.75 \mathrm{ml}$ in $100 \mathrm{ml}$ sterile distilled water.

\subsubsection{Trisodium phosphate:}

Tri-sodium orthophosphate 98\% (Alpha chemika) was used to prepare $3 \%, 5 \%$ and $8 \%$ solution by dissolving $3.06 \mathrm{ml}, 5.1 \mathrm{ml}$ and $8.16 \mathrm{ml}$ in $100 \mathrm{ml}$ sterile distilled water.

\subsubsection{Lactic acid:}

Pure lactic acid (Oxford laboratory) was used to prepare $0.75 \%, 1.25 \%$ and $2 \%$ solution by dissolving $0.833 \mathrm{ml}, 1.388 \mathrm{ml}$ and $2.222 \mathrm{ml}$ in $100 \mathrm{ml}$ sterile distilled water.

\subsection{Artificial contamination of samples of chicken carcasses with the tested microorganisms:}

Forty chicken samples were dipped in 500 $\mathrm{ml}$ sterile peptone water $0.1 \%$ (Merck, Germany) containing $24 \mathrm{hrs}-$ old cultures of the tested microorganisms (S. typhimurium, St. aureus , E.coli $\mathrm{O}_{157: \mathrm{H}_{7}}$ and $L$. monoctogens ) (10 samples for each microorganism). Subsequently, the inoculated chicken samples were left for 30 min. at room temperature $\left(25^{\circ} \mathrm{C}\right)$ to allow attachment and absorption of the inoculated bacteria. Then, the tested microorganisms (S. typhimurium, St. aureus, E.coli $\mathrm{O}_{157: \mathrm{H}_{7}}$ and L. monoctogens) were enumerated in the artificially contaminated samples to get the initial load before dipping treatments were performed.

Salmonella typhimurium was enumerated on XLD agar, while, St.aureus was 
enumerated on Baird Parker agar media, E.coli $\mathrm{O}_{157}: \mathrm{H}_{7}$ was enumerated on sorbitol MacConkey agar media and finally $L$. monoctogens was enumerated on Oxford agar media.

\subsection{Application of the tested decontaminators:}

Every ten contaminated chicken sample with known load of the tested microorganisms (S. typhimurium, $L$. monoctogens, St. aureus and E. coli $\mathrm{O}_{\left.157: \mathrm{H}_{7}\right)}$ were dipped into containers containing $500 \mathrm{ml}$ of chlorine $30 \mathrm{ppm}, 50$ ppm and $70 \mathrm{ppm}$, trisodium phosphate $3 \%$, $5 \%$ an $8 \%$ and lactic acid $0.75 \%, 1.25 \%$ and $2 \%$ at room temperature $(25 \pm 1 \mathrm{oC})$ for 15 min. The control samples were dipped in $500 \mathrm{ml}$ sterile distilled water. All the containers were properly labeled. Solutions covered all surface of the chicken samples. After dipping in the microbial decontaminators, all samples were removed and left at room temperature for $15 \mathrm{~min}$. to allow the decontamination effect. The experiment was repeated five times. Salmonella typhimurium, St. aureus, E.coli $\mathrm{O}_{157}: \mathrm{H}_{7}$ and L. monoctogens counts were conducted using the serial dilutions and spread plate technique after decontamination to determine the reduction percentages. The experiment was repeated five times.

\subsection{Statistical analysis:}

The data was statistically treated by oneway ANOVA using SPSS program for windows (Version 16) (SPSS Inc. Chicago, IL and USA) and Duncan's post hoc test with $\mathrm{p}<0.05$ considered to be statistically significant.

\section{RESULTS}

\subsection{Reduction by Chlorine :}

Table (1) reported that initial load of $S$. typhimurium was $7.34 \log \mathrm{CFU} / \mathrm{g}$, then it was reduced to $5.43 \pm 0.55,5.39 \pm 0.44$ and $5.20 \pm 0.45 \log \mathrm{CFU} / \mathrm{g}$ when dipped in 30 ppm, $50 \mathrm{ppm}$ and $70 \mathrm{ppm}$. Chlorine solutions, respectively, with a reduction percentages of $26.02 \%, 26.57 \%$ and 29.16 $\%$ as shown in table (2) and figure (1). St.aureus initial count was $5.67 \mathrm{log} \mathrm{CFU} / \mathrm{g}$ (1) , after dipping the counts were reduced to $4.86 \pm 0.12,4.78 \pm 0.13$ and $4.56 \pm 0.21 \log$ $\mathrm{CFU} / \mathrm{g}$, respectively, where the reduction percentages were $14.29 \%, 15.70 \%$ and $19.58 \%$, respectively ( table 2 and figure 1). E.coliO $157: \mathrm{H}_{7}$ counts inoculated on chicken parts were reduced when dipped in $30 \mathrm{ppm}, 50 \mathrm{ppm}$ and $70 \mathrm{ppm}$. Chlorine solutions from $5.96 \mathrm{log} \mathrm{CFU} / \mathrm{g}$ (initial load) to $5.39 \pm 0.32,4.97 \pm 0.20$ and $4.74 \pm 0.20 \mathrm{log}$ $\mathrm{CFU} / \mathrm{g}$, respectively, with reduction percentages of $9.56 \%, 16.61 \%$ and $20.47 \%$ (table 2 and figure 1 ). Finally, following treatment with chlorine solutions, reduction in L. monocytoges counts was shown from $5.29 \log \mathrm{CFU} / \mathrm{g}$ (initial load) to $4.41 \pm 0.33$, $4.20 \pm 0.38$ and $3.68 \pm 0.63 \log$ CFU/g in case of $30 \mathrm{ppm}, 50 \mathrm{ppm}$ and $70 \mathrm{ppm}$. , respectively (Table 1). Moreover, the results shown in table (2) and figure (1) revealed that counts were reduced in percentages of $16.64 \%, 20.60 \%$ and 30.43 $\%$ when treated by $30 \mathrm{ppm}, 50 \mathrm{ppm}$ and 70 ppm. chlorine solutions, respectively .

\subsection{Reduction by TSP :}

Salmonella typhimurium initial count was $7.34 \log \mathrm{CFU} / \mathrm{g}$, which was decreased to $4.78 \pm 0.20,4.64 \pm 0.37$ and $4.55 \pm 0.18 \mathrm{log}$ CFU/g by using 3,5 and $8 \%$ TSP, respectively, as shown in table (1). Regarding the results in table (2), the reduction percentages were $34.88 \%$, $36.78 \%$ and $38.01 \%$ when treated with $3 \%$, $5 \%$ and $8 \%$ TSP, respectively, which was shown in figure (1). Regarding

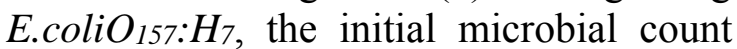
was $5.96 \log \mathrm{CFU} / \mathrm{g}$, when using TSP with concentrations of $3 \%, 5 \%$ and $8 \%$ the counts decreased to $4.92 \pm 0.78,4.68 \pm 0.23$ and $4.30 \pm 0.30 \log \mathrm{CFU} / \mathrm{g}$, respectively (table 1). Moreover, the reduction percentages were $17.45 \%, 21.48 \%$ and $27.85 \%$, respectively. (Table 2 and figure 1) 
Staphylococcus aureus initial count was $5.67 \log \mathrm{CFU} / \mathrm{g}$, which was reduced to $5.21 \pm 0.37,5.07 \pm 0.37$ and $4.10 \pm 0.36 \mathrm{log}$ $\mathrm{CFU} / \mathrm{g}$, respectively (table 1 ). Results in table (2) and figure (1) showed that the reduction percentages in $S$. aureus count were $8.11,10.58$ and $27.69 \%$. While $L$. monocytogens was reduced from initial count of 5.29 to $4.14 \pm 0.24,4.14 \pm 0.31$ and $3.96 \pm 0.22 \log \mathrm{CFU} / \mathrm{g}$, respectively, table (1). Such concentrations reduced L.monocytogens in percentages of $21.74 \%$, $21.74 \%$ and $25.14 \%$, respectively, table (2), and figure (1).

\subsection{Reduction by lactic acid :}

Salmonella typhimurium count was $7.34 \mathrm{log}$ $\mathrm{CFU} / \mathrm{g}$ (initial count), it was reduced to $4.74 \pm 0.17,4.34 \pm 0.23$ and $3.34 \pm 0.23 \log$ $\mathrm{CFU} / \mathrm{g}$, when inoculated chicken parts dipped in lactic acid solution in concentrations of $0.75 \%, 1.25 \%$ and $2 \%$, respectively. (table 1). On the other hand, the reduction percentages of S.typhimurium treated with the same concentrations were $35.42 \%, 40.87 \%$ and $54.50 \%$, respectively. (table 2, figure 1 ). St. aureus count was decreased from $5.67 \log \mathrm{CFU} / \mathrm{g}$ to $4.69 \pm 0.26,4.46 \pm 0.34$ and $4.09 \pm 0.29 \log$ $\mathrm{CFU} / \mathrm{g}$, respectively (table 1 ). Where the reduction percentages achieved in the experiment were $17.28 \%, 21.34 \%$ and $27.87 \%$ for the 3 concentrations of lactic acid used, respectively (table 2 , figure 1 ) . Moreover, E.coliO $157: \mathrm{H}_{7}$ initial count was decreased from $5.96 \mathrm{log} \mathrm{CFU} / \mathrm{g}$ to $4.88 \pm 0.07,4.77 \pm 0.12$ and $4.19 \pm 0.26 \log$ $\mathrm{CFU} / \mathrm{g}$, respectively (table 1 ), where the counts were reduced in percentages of $18.12 \%, 19.97 \%$ and $29.70 \%$, respectively. (table 2, figure 1). Finally, $L$. monocytogenes count, the initial load was decreased from $5.29 \mathrm{log} \mathrm{CFU} / \mathrm{g}$ to $4.08 \pm 0.39,3.69 \pm 0.26$ and $3.18 \pm .27 \mathrm{log}$ $\mathrm{CFU} / \mathrm{g}$, respectively (table 1 ). The reduction percentages were $22.87 \%$, $30.24 \%$ and $39.89 \%$, respectively (table 2 ).

Table (1): Effects of various concentrations of decontaminators on counts of food borne pathogens $(\log \mathrm{CFU} / \mathrm{g})$ in chicken carcasses samples.

\begin{tabular}{lcccc}
\hline & $\begin{array}{c}\text { Salmonella } \\
\text { spp }\end{array}$ & $\begin{array}{c}\text { Staph. } \\
\text { Aureus }\end{array}$ & E. coli O157:H7 & $\begin{array}{c}\text { L. } \\
\text { monocytogene } \\
\text { s }\end{array}$ \\
\hline Initial load & 7.34 & 5.67 & 5.96 & 5.29 \\
Control (D.W.) & $7.34 \pm 0.38 \mathrm{a}$ & $5.67 \pm 0.38 \mathrm{a}$ & $5.96 \pm 0.22 \mathrm{a}$ & $5.29 \pm 0.32 \mathrm{a}$ \\
Chlorine 30 & $5.43 \pm 0.55 \mathrm{~b}$ & $4.86 \pm 0.12 \mathrm{bc}$ & $5.39 \pm 0.32 \mathrm{~b}$ & $4.41 \pm 0.33 \mathrm{~b}$ \\
& \multicolumn{4}{c}{} \\
Chlorine 50 & $5.39 \pm 0.44 \mathrm{~b}$ & $4.78 \pm 0.13 \mathrm{~cd}$ & $4.97 \pm 0.20 \mathrm{c}$ & $4.20 \pm 0.38 \mathrm{bc}$ \\
Chlorine 70 & $5.20 \pm 0.45 \mathrm{bc}$ & $4.56 \pm 0.21 \mathrm{~d}$ & $4.74 \pm 0.20 \mathrm{c}$ & $3.68 \pm 0.63 \mathrm{~d}$ \\
TSP 3\% & $4.78 \pm 0.20 \mathrm{~cd}$ & $5.21 \pm 0.37 \mathrm{~b}$ & $4.92 \pm 0.78 \mathrm{c}$ & $4.14 \pm 0.24 \mathrm{bcd}$ \\
TSP 5\% & $4.64 \pm 0.37 \mathrm{~d}$ & $5.07 \pm 0.37 \mathrm{bc}$ & $4.68 \pm 0.23 \mathrm{c}$ & $4.14 \pm 0.31 \mathrm{bcd}$ \\
TSP 8\% & $4.55 \pm 0.18 \mathrm{~d}$ & $4.10 \pm 0.36 \mathrm{bc}$ & $4.30 \pm 0.30 \mathrm{~d}$ & $3.96 \pm 0.22 \mathrm{bcd}$ \\
Lactic acid 0.75\% & $4.74 \pm 0.17 \mathrm{~d}$ & $4.69 \pm 0.26 \mathrm{~cd}$ & $4.88 \pm 0.07 \mathrm{c}$ & $4.08 \pm 0.39 \mathrm{bcd}$ \\
Lactic acid 1.25\% & $4.34 \pm 0.23 \mathrm{~d}$ & $4.46 \pm 0.34 \mathrm{de}$ & $4.77 \pm 0.12 \mathrm{c}$ & $3.69 \pm 0.26 \mathrm{~cd}$ \\
Lactic acid 2\% & $3.34 \pm 0.23 \mathrm{e}$ & $4.09 \pm 0.29 \mathrm{e}$ & $4.19 \pm 0.26 \mathrm{~d}$ & $3.18 \pm .27 \mathrm{e}$ \\
\hline
\end{tabular}

The values represent mean \pm SD of three experiments. Mean values with different letters within the same column indicate significant difference $(P<0.05)$. 
Table (2): Reduction \% in food borne pathogens chicken carcasses samples dipped in different concentrations of decontaminators

\begin{tabular}{lcccc}
\hline & $\begin{array}{c}\text { Salmonella } \\
\text { spp. }\end{array}$ & Staph. Aureus & E. coliO157 & $\begin{array}{c}\text { L. } \\
\text { monocytogenes }\end{array}$ \\
\hline Chlorine 30 & 26.02 & 14.29 & 9.56 & 16.64 \\
Chlorine 50 & 26.57 & 15.70 & 16.61 & 20.60 \\
Chlorine 70 & 29.16 & 19.58 & 20.47 & 30.43 \\
TSP 3\% & 34.88 & 8.11 & 17.45 & 21.74 \\
TSP 5\% & 36.78 & 10.58 & 21.48 & 21.74 \\
TSP 8\% & 38.01 & 27.69 & 27.85 & 25.14 \\
Lactic acid 0.75\% & 35.42 & 17.28 & 18.12 & 22.87 \\
Lactic acid 1.25\% & 40.87 & 21.34 & 19.97 & 30.24 \\
Lactic acid 2\% & 54.50 & 27.87 & 29.70 & 39.89 \\
\hline
\end{tabular}

\section{DISCUSSION}

Chlorines are powerful germicides where its molecules penetrate the bacterial cell wall and react with key enzymes to prevent normal respiration and carbohydrate metabolism (Chmielewski \& Frank, 2003). Similar results were reported by Mart et al. (2013), where they reduced Salmonella contaminating chicken meat by $2.32 \log$ $\mathrm{cfu} / \mathrm{g}$ by treating inoculated parts with 50 ppm chlorine solution. On the other hand lower decontaminating effect was reported by Fabrizio et al. (2002), where salmonella counts were reduced $0.86 \log \mathrm{CFU} / \mathrm{g}$ by 20 to $50 \mathrm{ppm}$. chlorine solution . On contrary, higher reduction of Salmonella contaminating chicken meat was achieved by Whyte et al. (2001), where the mean count was $1.04 \log \mathrm{cfu} / \mathrm{g}, 25 \mathrm{ppm}$. chlorine solution caused complete decontamination, where Salmonella was not detected after dipping. The same reduction in St. aureus count achieved by $70 \mathrm{ppm}$ chlorine solution in this study ( from $5.67 \pm 0.38$ to $4.56 \pm 0.21$ $\log \mathrm{cfu} / \mathrm{g}$ ) was reported by Aksoy (2003), although they used 200 ppm chlorine solutions . On the other hand, Hecer et al. (2007) reduced $28.57 \%$ of St. aureus on chicken carcasses using $30 \mathrm{ppm}$ chlorine solution. Higher reduction percent of E.coliO $157: \mathrm{H}_{7}$ was reported by Hecer et al. (2007), where 30 ppm chlorine solution could reduce $31.25 \%$ of E.coli on chicken carcasses. Moreover, Sheen et al. (2012) indicated that permanent damage may have occurred to some $E$. coli $\mathrm{O}_{157}: \mathrm{H}_{7}$ cells, with chlorine exposure. The E. coli $\mathrm{O}_{157}: \mathrm{H}_{7}$ count reduction was around $3.0 \mathrm{log} \mathrm{cfu} / \mathrm{ml}$ at chlorine levels of $25-50 \mathrm{ppm}$. On contrary, Northcutt et al. (2005) reported that adding chlorine at $50 \mathrm{mg} / \mathrm{l}$ to the water in a broiler inside-outside bird spray wash station did not have any effect on the numbers of E. coli. Regarding reduction of L.monocytogenes, higher decontaminating effect was reported by Sheen et al. (2011) who stated that chlorine levels of 25 ppmto $50 \mathrm{ppm}$ reduced L. monocytogenes by 2.5 $\log \mathrm{cfu} / \mathrm{mL}$ in vitro. Moreover, in the presence of $45 \mathrm{ppm}$ chlorine, $L$. monocytogenes counts in chicken breast meat were reduced by about $0.12 \log$ most probable number/g (Goncalves et al., 2005). Another study made by Tsai et al. (1992) indicated that $40 \mathrm{ppm}$ chlorine reduced $L$. monocytogenes in poultry by only $37 \%$ to $50 \%$ in 3 to $5 \mathrm{~min}$. Lower reduction in $L$. monocytogenes count was achieved by $\mathrm{Oh}$ et al. (2014), where the bacterial populations were reduced by $0.03,0.06$, and $0.22 \mathrm{log} \mathrm{cfu} / \mathrm{g}$ after treatments of $50 \mathrm{ppm}$, $100 \mathrm{ppm}$, and $200 \mathrm{ppm}$ chlorine. At the cell membrane level, TSP at a high $\mathrm{pH}(\mathrm{pH} 12)$ helps to remove fat films and exerts surfactant or detergent effect. The loss of cell viability, membrane integrity and 
disruption of cytoplasmic and outer membranes of the microorganisms (Capita et. al., 2002). Lower reduction in salmonella count was reported by Del Rio et al. (2006) where S. typhimurium initial count was $5.5 \log \mathrm{cfu} / \mathrm{g}$, which was reduced to $3.5 \mathrm{log} \mathrm{cfu} / \mathrm{g}$ during decontamination using $12 \%$ TSP. Moreover, Fabrizio et al. (2002) reduced $1.41 \log 10$ Salmonella count by decontaminating chicken meat by $10 \%$ TSP. Lillard (1994) found that dipping chicken carcasses in a 10\% TSP solution for 15 minutes reduced Salmonella levels by 2 $\log 10$ cycles. On the other hand complete decontamination of Salmonella inoculated on chicken meat was achieved by Whyte et al. (2001), where Salmonella count was $1.04 \mathrm{log} \mathrm{cfu} / \mathrm{g}$ which in not detected after application of $10 \%$ TSP dipping. On the other hand, nearly similar results were achieved by Capita et al. (2002), where they reduced L. monocytogens count from 7.02 to $5.78 \mathrm{log} \mathrm{cfu} / \mathrm{g}$ using $8 \%$ TSP solution. Moreover, higher reduction in count was reported by Aksoy (2003) where the initial St. aureus count was $5.74 \mathrm{log} \mathrm{cfu} / \mathrm{g}$, which was decreased to $2.58 \mathrm{log} \mathrm{cfu} / \mathrm{g}$ by dipping inoculated chicken meat in $12 \%$ TSP solution. While in case of E.coliO157, Somers et al. (1994) reported that E. coli $\mathrm{O}_{157}: \mathrm{H}_{7}\left(105 \mathrm{cfu} / \mathrm{cm}^{2}\right.$ of biofilm cells) was eliminated by a 30 -second treatment with $1 \%$ TSP. On contrary, lower reduction in L.monocytogens count was reported by Del Rio et al. (2006), where the initial count was $6.25 \log \mathrm{cfu} / \mathrm{g}$, which was decreased to 5.25 $\log \mathrm{cfu} / \mathrm{g}$ by dipping inoculated chicken meat in $12 \%$ TSP solution. The antimicrobial activity occurs through the diffusion of lactic molecules in to microbial cells until equilibrium is reached, in accordance with the $\mathrm{pH}$ gradient, causing membrane disruption, inhibition of essential metabolic reactions, stress on intracellular $\mathrm{pH}$ homeostasis and accumulation of toxic anions and ultimate death of microbial cells (Ibrahim et al. 2008) . Similar results of S. typhimiurium reduction were reported by Dan et al. (2012), who reduced $2.89 \log _{10}$ of salmonella typhimurium count by dipping chicken meat in $1 \%$ and $2 \%$ lactic acid. While $100 \%$ reduction percent was achieved in the same study when the sample was treated by $3 \%$ lactic acid. Moreover, Sudershan et al. (2011) examined the decontaminating effect of $0.5 \%, 1 \%, 2 \%$ and 3\% lactic acid on Salmonella, where the count was reduced from $2.17 \mathrm{log} \mathrm{cfu} / \mathrm{g}$ to not detectable level. Moreover, Mulder et al., (1978) reported $2 \log \mathrm{cfu} / \mathrm{g}$ reductions in Salmonella count on chicken meat treated by $1 \%$ lactic acid. Moreover, higher reduction percentages were achieved by Hecer and Guldas (2011), where E. coliO157 counts were reduced as $16 \%$ and $56 \%$ with lactic acid solution ( 0.5 and $1.0 \%)$. On the other hand, relatively higher reduction percentage was achieved by Aksoy (2003) who decreased St. aureus count on chicken meat from 5.74 to $2.93 \log \mathrm{cfu} / \mathrm{g}$ by dipping inoculated samples in $2 \%$ lactic acid solution. While, nearly similar results were reported by Sudershan et al (2011) where they examined the effect of different concentration of lactic acid $(0.5 \%, 1 \%, 2 \%$ and $3 \%$ ) on St. aureus contaminating chicken meat, where counts reduced from $3.08 \log \mathrm{cfu} / \mathrm{g}$ to $1.79 \log \mathrm{cfu} / \mathrm{g}$. Finally, higher reduction in L. monocytogens count was reported by Dan et al. (2012), where the counts decreased 1.56 to $4.45 \log _{10}$ after dipping chicken meat in $1 \%$ and $2 \%$ lactic acid solutions. From the obtained results, it could be realized that S.typhimurium was the most reduced microorganism, followed by L. monocytogenes, then E.coliO157 and finally $S$. aureus, which was the least reduced microorganism. On the other hand this study proved that lactic acid $2 \%$ was the best decontaminator (among the examined decontaminators), where it achieved the highest reduction percentage.

\section{REFERENCES}

Aksoy, A. 2003. Evaluation of surface decontamination applications in some uncooked chicken meat and fresh cut vegetables. Graduate thesis. Istanbul 
Technical University Faculty of Science.

Anang, D. M., Rusul, G., Bakar, J., Ling, F. H. 2007. Effects of lactic acid and lauricidin on the survival of Listeria monocytogenes, Salmonella enteritidis and Escherichia coli O157:H7 in chicken breast stored at 4uC. Food Control 18:961-969.

Barbut, S. 2002. Microbiology and sanitation, p. 315-378. In S. Barbut, Poultry products processing, an industry guide. CRC Press, Boca Raton, FL.

Bautista, D.A., Sylvester, N., Barbut, S., Griffiths, M.W. 1997. The determination of efficacy of antimicrobial rinses on turkey carcasses using response surface designs. Food Microbiol. 34:279292.

Bremner, A., Johnston, M. 1996. Control of microbial hazards in poultry processing, p. 125-148. In A. Bremmer and M. Johnston, Poultry. W. B. Saunders Company Ltd., London.

Capita, R., Alonso-Calleja, C., GarciaFernandez, M., Moreno, B. 2002. Activity of trisodium phosphate compared with sodium hydroxide wash solutions against Listeria monocytogens attached to chicken skin during refrigeration storage. Food microbiology, 19: 57-63

Chmielewski, R.A.N., Frank, J.F. 2003. Biofilm formation and control in food processing facilities. Comprehensive Reviews in Food Science and Food Safety, 2:22 - 32 .

Dan, S.D., Mihaiu, M., Mihaiu, R., Jecan, C., Lapusan, A. 2012. The Effect of Acetic and Lactic Acid for Reducing the Prevalence of Pathogen Load on Poultry. Bulletin USAMV serie Medicină Veterinară. 69:1-2.

Del Ri'o, E., Capita, R., Prieto, M., AlonsoCalleja, C. 2006. Comparison of pathogenic and spoilage bacterial levels on refrigerated poultry partsfollowing treatment with trisodium phosphate. Food Microbiology 23:195-198

Fabrizio, K.A., Sharma, R.R., Demirci, A., Cutter, C.N. 2002. Comparison of Electrolyzed Oxidizing Water with Various Antimicrobial Interventions to Reduce Salmonella Species on Poultry. Poultry Science 81:15981605.

Goncalves, A.C., Almeida, R.C.C., Alves, M. A. O., Almeida, P. F. 2005. Quantitative investigation on the effects of chemical treatments in reducing Listeria monocytogenes populations on chicken breast meat. Food Control 16:617-622

Hardin, M. D., Acuff, G. R., Lucia, L. M., Oman, J. S., Savell, J. W. 1995. Comparison of methods for decontamination from beef carcass surfaces. J. Food Prot. 58: 368-374.

Hecer, C., Balci, F., Udum, C. D. 2007. The Effects of Ozone and Chlorine Applications on Microbiological Quality of Chickens During Processing. J. BIOL. ENVIRON. SCI., 1(3):131-138

Hecer, C., Guldas, M. 2011. Effects of lactic acid, fumaric acid and chlorine dioxide on shelf life of broiler wings during storage. African Journal of Microbiology Research. 5(23):38803883, 23.

Ibrahim, S. A., Yang, H., Seo, C. W. 2008. Antimicrobial activity of lactic acid and copper on growth of Salmonella and Escherichia coli 0157:H7 in laboratory medium and carrot juice. Food Chem. 109: 137-143

Kanellos, T. S., Burriel, A. R. 2005. The in vitro bactericidal effects of the food decontaminants lactic acid and trisodium phosphate. Food Microbiol. 22:591-594.

Lillard, H. S. 1994. Effect of trisodium phosphate on salmonellae attached to chicken skin. J. Food Protect. 57(6): 465-469. 
Mart, S., Williams, S. K., Sharma, C. S. 2013. Reduction of Salmonella Typhimurium on Poultry Skin Utilizing Sodium Metasilicate in Prechill and Postchill Applications. International J. of Poultry Science 12 (9):501-504

Mulder, R. W. A. W., Van der Hulst, M.C., Bolder, N. M. 1978. Salmonella decontamination of broiler carcasses with lactic acid, Lcysteine and hydrogen peroxide. Poultry Sci. 66: 1555-1557.

Northcutt, J. K., Jones. D. R. 2004. A survey of water use and common industry practices in commercial broiler processing facilities. J. Appl. Poult. Res. 13:48-54.

Northcutt, J. K., Smith, D. P., Musgrove, M. T., Ingram, K. D., Hinton, A. Jr. 2005. Microbiological Impact of Spray Washing Broiler Carcasses Using Different Chlorine Concentrations and Water Temperatures. Poultry Science 84:1648-1652

Oh, S.R, Park, S.Y., Ha, S. D. 2014. Combined effects of chlorine and thiamine dilauryl sulfate on reduction of Listeria monocytogenes in chicken breast and development of predictive growth models. Poultry Science 93:1503-1510

Okolocha, E. C., Ellerbroek, L. 2005. The influence of acid and alkaline treatments on pathogens and the shelf life of poultry meat. Food Control 16:217-225.

Podolak, R. K., Zayas, J. F., Kastner, C. L., Fung, D. Y. C. 1996. Reduction of bacterial populations on vacuumpackaged ground beef patties with fumaric and lactic acids. Journal of Food Protection. 59:1037-1040.

Sheen, S., Hwang, C. A., Juneja, V. K. 2011. Modeling the impact of chlorine on the behavior of Listeria monocytogenes on ready-to-eat meats. Food Microbiol. 28:10951100.
Somers, E. B., Schoeni, J. L.,Wong, A. C. L. 1994. Effect of trisodium phosphate on biofilm and planktonic cells of Campylobacter jejuni, Escherichia coli O157:H7, Listeria monocytogenes and Salmonella typhimurium. Int. J. Food Microbiol. 22(4):269-276.

Sudershan, R.V., Kumar, N. R., Kashinath, L., Bhaskar, V., Polasa, K. 2011.

Antimicrobial Activity of Lactic acid on the Growth of Selective

Foodborne Pathogens in Raw Chicken. Internet Journal of Food Safety, 13:124-130

Tsai, L. S., Schade, J. E., Molineux, B. T. 1992. Chlorination of poultry chiller water: Chlorine demand and disinfection efficiency. Poult. Sci. 71:188-196.

USDA, 2002. The use of trisodium phosphate as an antimicrobial agent in poultry processing in the United States. USDA-FSIS, Office of International Affairs.

Whyte, P., Collins, J. D., Gill, K. M, Monahan, C., Mahony, H. O. 2001. Quantitative Investigation of the Effects of Chemical Decontamination Procedures on the Microbiological Status of Broiler Carcasses during Processing. J. of Food Protection. 64 (2): 179-183. 